\title{
COMPARISON OF THE POTENCY OF SEVERAL FLUORIDE-BASED VARNISHES AS AN ANTICARIOGENIC ON CALCIUM, PHOSPHATE, AND FLUORIDE ION LEVELS
}

\author{
SRI ANGKY SOEKANTO ${ }^{1 *}$, NAMIRA ROSITHAHAKIKI ${ }^{1}$, DEWI FATMA SUNIARTI ${ }^{1}$, MOHAMAD SAHLAN ${ }^{2}$ \\ ${ }^{1}$ Department of Oral Biology, Faculty of Dentistry, Universitas Indonesia, Jakarta, Indonesia. ${ }^{2}$ Department of Chemical Engineering, Faculty \\ of Engineering, Universitas Indonesia, Jakarta, Indonesia. Email: sriangky@ui.ac.id \\ Received: 16 September 2017, Received and Accepted: 06 November 2017
}

\section{ABSTRACT}

Objectives: The purpose of this present study was to analyze several fluoride-based varnishes: Silver diamine fluoride (SDF), nanosilver fluoride (NSF), and propolis fluoride (PPF). Fluoride-based varnish is proven to act as antibacterial and remineralization agents that arrested caries progression with minimal side effects. SDF, the golden standard for this study, was compared to NSF and PPF, which were made in our own laboratory, to evaluate their ability to release calcium, phosphate, and fluoride ions and act as anticariogenic agents.

Methods: Human dentin discs were prepared and divided into control groups and treatment groups with SDF (38\%), NSF (3.16\%, 3.66\%, and 4.16\%), and PPF (3\%,6\%, and 10\%). The dentin discs were demineralized using a demineralization solution ( $\mathrm{pH} 4.4)$ for $96 \mathrm{~h}$. Each dentin disc in the treatment group received a topical application of various fluoride-based varnishes and then was subjected to pH-cycling for 8 days. The quantity of calcium, phosphate, and fluoride ions on the dentin discs surface was compared after being detected using energy dispersive X-ray spectroscopy.

Results: The result revealed that the calcium ion levels in groups NSF and PPF increased significantly compared to SDF. The levels of phosphate ions and fluoride ions in groups NSF and PPF increased significantly compared to SDF.

Conclusion: The study concluded that, in contrast to SDF, the prepared NSF and PPF fluoride-based varnishes were shown to release calcium, phosphate, and fluoride ions in this study. Hence, NSF and PPF fluoride-based varnishes are promising as anticariogenic agents.

Keywords: Caries, Calcium ion, Phosphate ion, Fluoride ion, Silver diamine fluoride, Nano silver fluoride, Propolis fluoride, Demineralization, Remineralization.

(c) 2017 The Authors. Published by Innovare Academic Sciences Pvt Ltd. This is an open access article under the CC BY license (http://creativecommons. org/licenses/by/4. 0/) DOI: http://dx.doi.org/10.22159/ijap.2017.v9s2.14

\section{INTRODUCTION}

Dental caries is the most common oral health problem worldwide. Around $60-90 \%$ of school children in the world experience dental caries, and most of them do not have proper treatment [1]. Dental caries is represented microscopically as the demineralization of the hard tissue of the teeth. Caries is a multifactorial disease with factors that include a host (saliva and teeth structure), cariogenic microorganism (Streptococcus mutans), diet (carbohydrate), and time [2].

When caries reaches dentin, there are two different surfaces microscopically: Infected dentin and affected dentin. Infected dentin affects the outer surface and is irreversible, infected, unable to remineralize, and must be cleaned. Affected dentin affects the inner surface and is reversible, uninfected, and can be left. Affected dentin does not have to be excavated because it has the ability to be remineralized if there are enough fluoride, calcium, and phosphate ions on the environment [3].

Silver diamine fluoride (SDF) $\left[\mathrm{Ag}\left(\mathrm{NH}_{3}\right)_{2} \mathrm{~F}\right]$ has an anticariogenic effect because it releases fluoride ions rapidly to help remineralization. SDF is recommended by dentist to prevent the progress of caries mostly in Japan, Australia, and the United States. The product was cleared for sale in the United States in August 2014 by the Food and Drug Administration as a Class II medical device [4].

Fluoride and silver interact to form fluorapatite, hydroxyapatite, and silver phosphate, which increases mineral density, increases the hardness of hydroxyapatite and fluorapatite crystals, and decreases the depth of the cavity.
Unfortunately, this product stains the teeth and has a metallic taste. One study states that calcium fluoride and silver phosphate cannot be dissolved and precipitated at the dentin surface, hence acting as tooth surface protector $[5,6]$.

Nanosilver fluoride (NSF) is another anticariogenic agent formulated to diminish the weakness of SDF. It forms black stains on the caries lesion and could irritate soft tissue. The black stain is due to the oxidation of silver ions on SDF, and the soft tissue irritation is reversible but may cause pain. There has not been any research about the side effects of NSF, but there are some studies regarding nanosilver, which is the main component of NSF.

A study by Braydich-Stolle et al. stated that there was a change in the mitochondria function of a rat liver in a cytotoxicity test using silver nanoparticles. Another study stated that silver nanoparticles could have serious toxic effects on the human male's reproductive system [7-9]. NSF was made in our laboratory, following the formula that has been reported, comparing to propolis fluoride (PPF) and SDF in their ability to release calcium, phosphate, and fluoride ions as a parameter to remineralize the tooth that was analyzed [10].

Propolis was chosen in this study as a natural product and is expected to be safer than the silver or nanosilver used in SDF and NSF. This study was also to observe the stability of the PPF mixture when used as a fluoride varnish. PPF consists mainly of propolis and fluoride made in the Laboratory of Bioprocessing in the Faculty of Chemical Engineering, Universitas Indonesia. It contains flavonoid and cinnamic acid, which act as antibacterial, antivirus, and antifungal agents. 
Flavonoid acts as an antibacterial by inhibiting the glucosyltransferase enzyme. This enzyme helps glucan formation, which helps bacteria to adhere to enamel and form a biofilm matrix. Pure propolis also contains a low level of calcium that could help remineralization. Fluoride ions in PPF act as a remineralization agent because of their ability to increase tooth endurance to acid by forming fluorapatite. PPF was expected to have fewer side effects of SDF and NSF [11-14].

Despite the advantages of SDF in preventing the progression of caries, it also has disadvantages, so other agents with the same or better as an anticariogenic but fewer disadvantages are needed. It is important to determine whether NSF and PPF have a remineralization effect that is as good as that of SDF through the release of calcium, phosphate, and fluoride ions. This study was conducted to evaluate NSF and PPF fluoride varnish in this regard and as an alternative therapy to prevent the progression of caries.

\section{MATERIALS AND METHODS}

\section{Materials}

SDF was made from $6.816 \mathrm{~g}$ of $\mathrm{AgNO}_{3}$ in a vial with $5 \mathrm{ml}$ of distilled water, which was then homogenized using a vortex. Then, $1.47 \mathrm{~g}$ of $\mathrm{NH}_{4} \mathrm{~F}$ was added into the vial and once again homogenized in $\mathrm{pH} 4$. Then, ammonia was added to the mixture up to $13.2 \mathrm{ml}$ until pH 7 was achieved. The vial was then covered with black plastic and kept at $8^{\circ} \mathrm{C}$ in the refrigerator until use.

NSF was made in three different concentrations $(3.16 \%, 3.66 \%$, and $4.16 \%$ ) by adding $\mathrm{AgNO}_{3}$. Gelatin ( $5 \mathrm{ml}$ ) was added as a stabilizer to each concentration to avoid sedimentation by mixing it at $70^{\circ} \mathrm{C}$. Glucose (13.3 $\mathrm{g}$ in $40 \mathrm{ml}$ distilled water) was then mixed well until nanoparticles were formed. The nanoparticle suspension was combined with $4.4 \mathrm{~g}$ of $\mathrm{NH}_{4} \mathrm{~F}$ for $1 \mathrm{~min}$ and then maintained at $8^{\circ} \mathrm{C}$.

PPF was made in three different concentrations. First, $5 \mathrm{~g}$ of $\mathrm{NH}_{4} \mathrm{~F}$ was added to $50 \mathrm{ml}$ aquades and mixed until homogenous. A surfactant solution was made from $96 \%$ ethanol and tween 80 . The solution was mixed by adding propolis at three different concentrations; PPF was made into $3 \%, 6 \%$, and $10 \%$ concentrations and kept at $8^{\circ} \mathrm{C}$. SDF, NSF, and PPF were made by the Laboratory of Bioprocessing in the Faculty of Engineering, Universitas Indonesia.

\section{Methods}

This was an experimental laboratory study using human dentin discs. Human premolar teeth were obtained from extracted teeth before the orthodontic treatment of subjects, who were mostly aged 13-20 years with no caries, calculus, or defects at the crowns of the teeth. Ninety human dentin discs of $2 \mathrm{~mm}$ thickness were divided into negative and positive control groups. The negative control was for dentin disc without any treatment or demineralization, and the positive control was for dentin disc that was demineralized.

Treatment of the groups with concentrations of SDF 38\%, NSF 3.16\%, NSF $3.66 \%$, NSF $4.16 \%$, PPF $3 \%$, PPF $6 \%$, and PPF $10 \%$ was performed first on the demineralized dentin discs. Each group consisted of 10 human dentin discs. The different concentrations of NSF and PPF were based on a preliminary study and ranged to obtain a good fluoride varnish with a lower concentration with a good efficacy. The dentin discs of the negative control were soaked in distilled water solution. The dentin discs in the positive control and the treatment group were demineralized using demineralization solution $(\mathrm{pH} \mathrm{4.4)} \mathrm{for} 96 \mathrm{~h}$ to get white spot appearance. The dentin discs in the positive control group were rinsed with distilled water solution and dried. The dentin discs in the treatment group received the topical application of the fluoridebased varnish. This varnish was applied using a special applicator brush on all dried surfaces of the teeth. After the varnish had set, the dentin discs in the treatment group were subjected to $\mathrm{pH}$-cycling using a demineralization solution ( $\mathrm{pH} 4.4$ ) for $30 \mathrm{~min}$ and a remineralization solution ( $\mathrm{pH} 7$ ) for $10 \mathrm{~min}$.
This cycle was performed 6 times per day for 8 days at room temperature. The quantity of calcium, phosphate, and fluoride ions (\%) on the surfaces of the dentin discs was detected using energy dispersive X-ray (EDX). The data were analyzed using statistical tests. The ShapiroWilk normality test showed that the positive control and the negative control groups did not have normal data distribution $(\mathrm{p}<0.05)$, while the data distribution in treatment group had a normal distribution ( $p>0.05)$. Kruskal-Wallis and Mann-Whitney tests were used to analyze the difference between treatment groups.

This study was conducted at the Forensic Laboratory of Indonesian Police and Oral Biology Laboratory at the Faculty of Dentistry, Universitas Indonesia, Jakarta, Indonesia.

\section{RESULTS AND DISCUSSION}

Propolis is known to have an antibacterial activity [15]. The previous study showed that propolis is good as an anticariogenic agent; however, the composition of propolis is different due to its geographical distribution [16]. Propolis extracted from Tetragonula sp. stingless bee that is farmed in Universitas Indonesia was used in this study. Preliminary study showed that this propolis has a strong antibacterial effect on $S$. mutans and Enterococcus faecalis. This present observation was to confirm that the mixture of propolis and silver nano fluoridebased varnish has a potency as an anticariogenic by releasing three main components: Calcium, phosphate, and fluoride ion.

These three ions play an important role in balancing demineralization and remineralization processes and modifying the susceptibility of the tooth to caries progression [17]. In the present study, NSF was made by a modification of the procedures of Dos Santos et al., green synthesis methods were used, and distilled water was chosen as the solvent, gelatin as the stabilizer, and glucose as the reducing agent [18].

Gelatin is a natural protein, and it is nontoxic, biocompatible, and can be ionized. Gelatin can stabilized a surface by the spatial arrangement of the atoms inside a molecule, so its main function is as stabilizer. To reduce silver cations to silver atoms, glucose was used as a reducing agent. The gradual changes in color from light brown to a darker brown were sign that the solution formed nanoparticles [19].

\section{Calcium ion calculation on dentin disc surface}

The pH-cycling process performed on the positive control and treatment group is a method used to simulate teeth in the oral cavity. This research was done by creating a negative control group (without demineralization exposure), a positive control, and treatment groups in a demineralization solution. There was a statistically significant difference $(p \leq 0.05)$ between group NSF 3.16\% $(p=0.019)$ and $3.66 \%$ $(\mathrm{p}=0.008)$ and PPF $3 \%(\mathrm{p}=0.034)$ and $10 \%(\mathrm{p}=0.019)$ compared to the positive control. There was no statistically significant difference between the negative control compared to group NSF $3.66 \%(\mathrm{p}=0.705)$ and PPF $10 \%(\mathrm{p}=0.650)$. The mean of the total calcium ions (\%) in group NSF $3.16 \%$ was $10.7 \pm 5.43$ and $3.66 \%$ was $10.64 \pm 4.31$, and PPF $3 \%$ was $9.46 \pm 4.23$ and $10 \%$ was $10.52 \pm 5.11$, while the positive control group was $5.36 \pm 3.36$. The statistical test showed that there was no significant difference between the total calcium ions (\%) for each concentration of NSF and PPF (Fig. 1).

The calcium ion number in the NSF group and PPF group was not dose dependently. This method is a modification of two previous methods conducted by Mei et al. and Reynolds et al. [20,21]. All the dentin discs from the control and treatment groups were dried and tested with EDX.

The number of calcium ions was tested because when carious teeth are remineralized, the amount of calcium will increase due to the formation of hydroxyapatite crystals and fluorapatite. This research used SDF 38\% as the gold standard because it is proven to effectively arrest the dental caries process [22-24]. Meanwhile, NSF 3.16\%, NSF 3.66\%, NSF 4.16\%, PPF $3 \%$, PPF $6 \%$, and PPF $10 \%$ were used as the new concentration of varnishes because their efficacy as anticariogenic agents is still not yet 


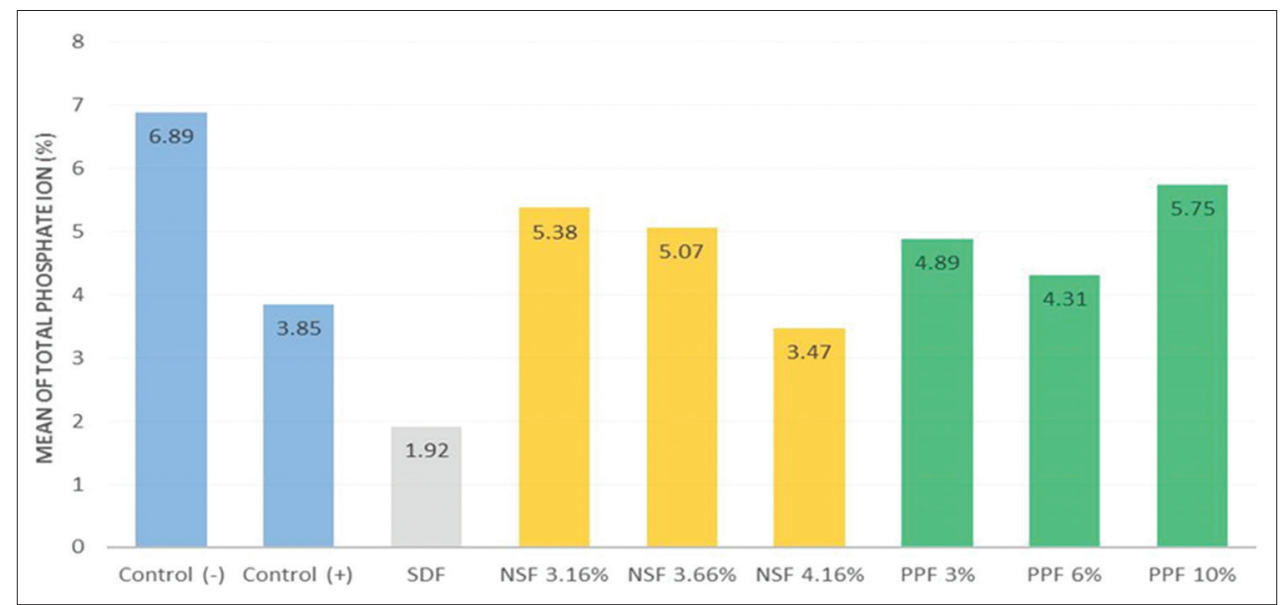

Fig. 1: Distribution of calcium ion levels (\%) on the control group and treatment group

known. Based on the results, the calcium ions in demineralized teeth with NSF 3.66\% and PPF 10\% increased but not with SDF 38\% while NSF and PPF at each concentration had the same ability to increase the calcium ions in demineralized teeth.

This result is different to that of Mei et al., who stated that the application of SDF 38\% could remineralize the dentin [20]. This may be because the EDX method only measures the tooth surface covered with varnish containing silver and fluoride and the calcium ions thus cannot be detected optimally. Research by Targino et al. showed parallel results with this research, wherein NSF was proven to be similarly effective to SDF in arresting the dental caries process without leaving black stains on the teeth [25].

Phosphate ion calculation on dentin disc surface

Fig. 2 showed that there was a statistically significant difference $(p \leq 0.05)$ between the negative control group $(\mathrm{p}=0.002)$ and the SDF group $(\mathrm{p}=0.019)$ compared to the positive control. There was no statistically significant difference between group NSF $3.16 \%(\mathrm{p}=0.131)$, PPF $3 \%$ $(\mathrm{p}=0.059)$, and $10 \%(\mathrm{p}=0.174)$ compared to the negative control. The mean of the total phosphate ions on the negative control group was $6.89 \pm 1.76$, the SDF group was $1.92 \pm 1.28$, and the positive control group was $3.85 \pm 1.83$. The statistical tests showed that there was no significant difference between the total phosphate ions for each concentration of NSF and PPF. The increasing phosphate ion numbers in the NSF group were not directly proportional to increasing silver concentration. The increasing phosphate ion number in the PPF group was also not directly proportional to increasing propolis concentrations.

\section{Fluoride ion calculation on the dentin disc surface}

There was a statistically significant difference $(p \leq 0.05)$ between the negative control group ( $\mathrm{p}=0.007)$ and group NSF $3.66 \%(\mathrm{p}=0.027)$ compared to the positive control. There was a statistically significant difference between SDF ( $\mathrm{p}=0.466)$ and NSF 4.16\% ( $\mathrm{p}=0.091$ ) compared to the negative control. The mean of the total fluoride ions on the negative control group was $0.02 \pm 0.054$, NSF $3.66 \%$ was $0.39 \pm 0.24$, and the positive control group was $0.17 \pm 0.14$. There was a statistically significant difference in the total fluoride ions between NSF $2.16 \%$ and $4.16 \%$ and between $3.66 \%$ and $4.16 \%$. The statistical tests showed that there was no significant difference between total fluoride ions for each concentration of PPF. The increasing number of fluoride ions in the NSF group and PPF group were not dose dependently (Fig. 3). Statistically, there were no significant differences in the numbers of phosphate ions in each concentration of NSF and PPF (Fig. 4).

The increase of phosphate ions in PPF and NSF was opposite to the increasing concentration of silver and propolis, respectively. Statistically, there was a significant difference in the numbers of fluoride ions (\%) for each concentration of PPF. The increasing numbers of fluoride ions

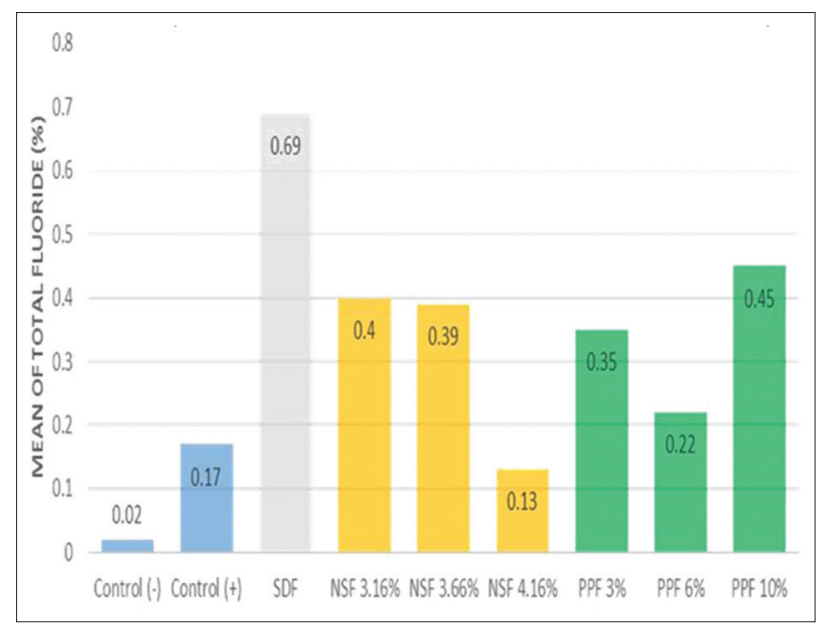

Fig. 2: Distribution of phosphate ion levels (\%) in the control group and the treatment group

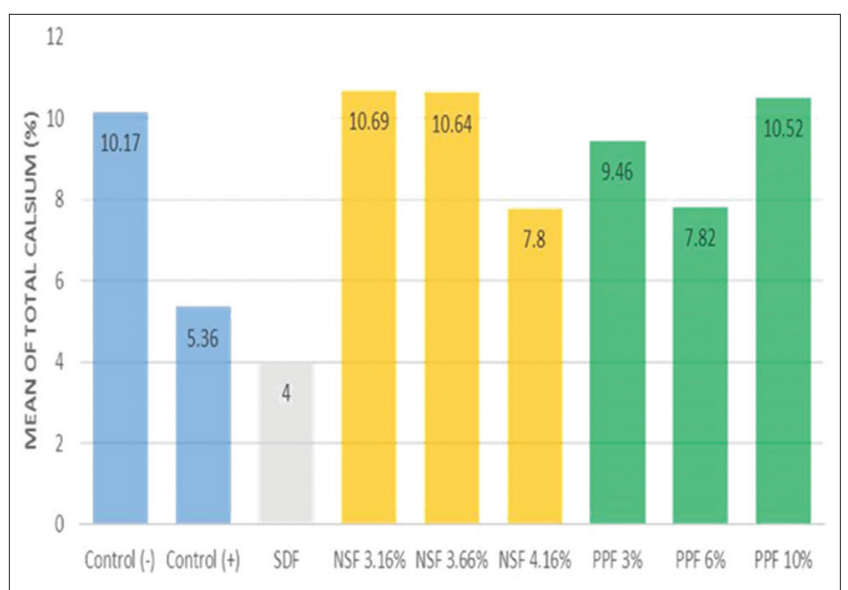

Fig. 3: Distribution of fluoride ion levels (\%) in the control group and the treatment group

in NSF and PPF had an inverse relationship to the concentration of silver and propolis.

Based on the comparison of total ions (calcium, phosphate, and fluoride), NSF can increase the number of fluoride ions in demineralized teeth as it is seen to have a statistically significant differences when compared with the positive control, while SDF showed no significant differences 


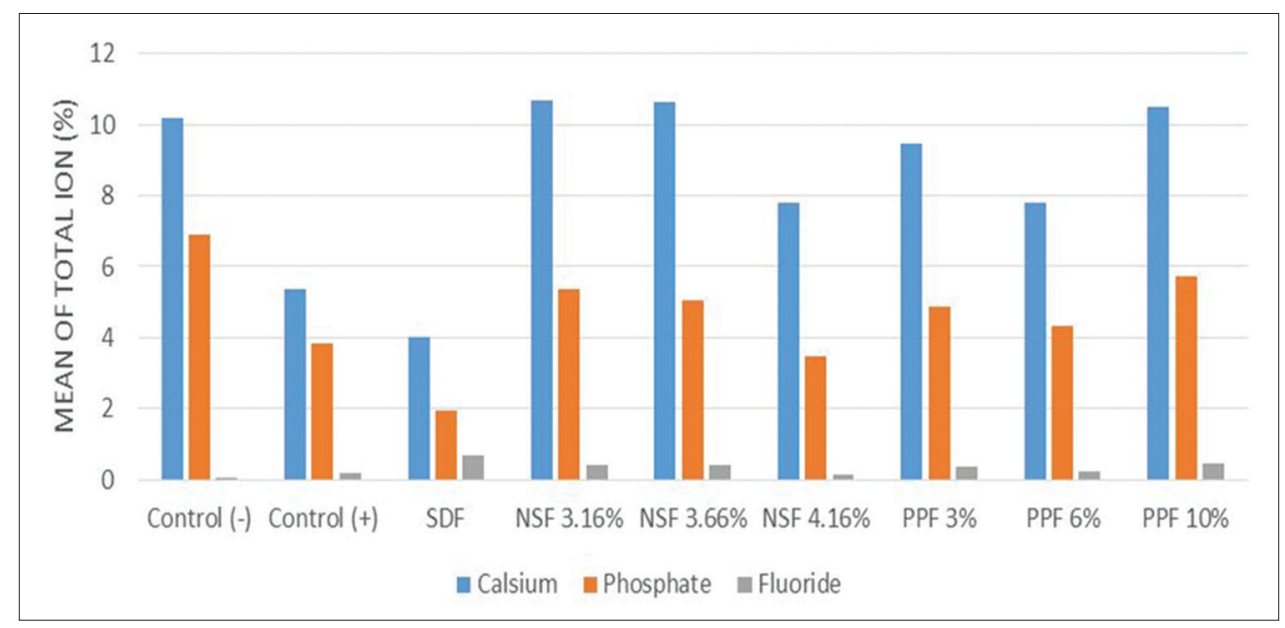

Fig. 4: Comparison of total distribution of calcium, phosphate, and fluoride ions in the control group and the treatment group

when compared to the positive control. All fluoride-based varnish in this present study had an ability to increase calcium, phosphate, and fluoride ions from demineralized teeth.

Fluoride ion is known to bind calcium and phosphate ions in their environment, i.e., saliva, to form calcium fluoride $\left(\mathrm{CaF}_{2}\right) \cdot \mathrm{CaF}_{2}$ easily dissolves in water, although SDF varnish that is high in $\mathrm{pH}$ can cause $\mathrm{CaF}_{2}$ to not easily dissolve. $\mathrm{CaF}_{2}$ is important as a fluoride reservoir when the oral environment becomes acidic, because of the metabolism of bacteria. $\mathrm{CaF}_{2}$ will be prevented from dissolving by the protein phosphate coating in saliva [26-28]. Huang et al. in 2014 found that propolis contains a small amount of metal compounds [29], this is in accordance to this study. Moreover, scientists have shifted their interest from chemical or physical methods to biological methods as it does not involve a combination of abusive or toxic chemicals to human health or any involvement of immense machines or equipment [30].

\section{CONCLUSION}

This study concludes that NSF and PPF were proven to have the ability to release calcium, phosphate, and fluoride ions and revealed similarities to SDF. NSF and PPF fluoride-based varnishes have potency as an anticariogenic and were shown to release ions that are needed to remineralize the surface of dentin. NSF and PPF fluoride-based varnishes are promising as anticariogenic agents.

\section{REFERENCES}

1. FDI World Dental Federation. Oral Health Worldwide Report. Geneva, Switzerland: FDI World Dental Federation; 2014. p. 1-24.

2. Roberson TM, Heymann H. Studervant's Art and Science of Operative Dentistry. $4^{\text {th }}$ ed. North Carolina: Mosby, Inc.; 2002.

3. Hume GJ. Preservation and Restoration of Tooth Structure. $2^{\text {nd }}$ ed. Queensland: Rob Watts; 2005 .

4. Chu CH, Lo EC, Lin HC. Effectiveness of silver diamine fluoride and sodium fluoride varnish in arresting dentin caries in Chinese pre-school children. J Dent Res 2002;81:767-70.

5. Gupta A, Sinha N, Logani A, Shah N. An ex vivo study to evaluate the remineralizing and antimicrobial efficacy of silver diamine fluoride and glass ionomer cement Type VII for their proposed use as indirect pulp capping materials-Part I. J Conserv Dent 2011;14:113-6.

6. Horst JA, Ellenikiotis H, Milgrom PL. UCSF protocol for caries arrest using silver diamine fluoride: Rationale, indications and consent. J Calif Dent Assoc 2016;44:16-28.

7. Braydich-Stolle L, Hussain S, Schlager JJ, Hofmann MC. In vitro cytotoxicity of nanoparticles in mammalian germline stem cells. Toxicol Sci 2005;88:412-9.

8. Panyala NR, Peña-Méndez EM, Havel J. Silver or silvernanoparticles: A hazardous threat to the environment and human health? J Appl Biomed 2008;6:117-29.
9. Prabhu S, Poulose EK. Silver nanoparticles: Mechanism of antimicrobial action, synthesis, medical applications, and toxicity effects. Int Nano Lett 2012;2:32.

10. Burns J, Hollands K. Nano silver fluoride for preventing caries. Evid Based Dent 2015;16:8-9.

11. Santos VE Jr, Vasconcelos Filho A, Targino AG, Flores MA, Galembeck A, Caldas AF Jr, et al. A new "silver-bullet" to treat caries in children-nano silver fluoride: A randomised clinical trial. J Dent 2014;42:945-51.

12. Yee R, Holmgren C, Mulder J, Lama D, Walker D, van Palenstein Helderman W. Efficacy of silver diamine fluoride for arresting caries treatment. J Dent Res 2009;88:644-7.

13. Ahuja V, Ahuja A. Apitherapy-a sweet approach to dental diseases-part II: Propolis. J Acad Adv Dent Res 2010;1:81-6.

14. Santana EQ, Almeida AA, Jabor AP, Chung MC. Determination of calcium and magnesium in hydroethanolic extracts of propolis by atomic absorption flame spectrophotometry. Rev Ciênc Farma Bás Apl 2009;29:77-80.

15. Kuropatnicki AK, Szliszka E, Krol W. Historical aspects of propolis research in modern times. Evid Based Complement Alternat Med 2013;2013:964149.

16. Libério SA, Pereira AL, Araújo MJ, Dutra RP, Nascimento FR, Monteiro-Neto V, et al. The potential use of propolis as a cariostatic agent and its actions on mutans group streptococci. J Ethnopharmacol 2009;125:1-9.

17. Abou Neel EA, Aljabo A, Strange A, Ibrahim S, Coathup M, Young AM, et al. Demineralization-remineralization dynamics in teeth and bone. Int J Nanomedicine 2016;11:4743-63.

18. Pulit J, Banach M. Preparation of nanocrystalline silver using gelatin and glucose as stabilizing and reducing agents, respectively. Dig J Nanomater Biostruct 2013;8:787-95.

19. Kumari RM, Thapa N, Gupta N, Kumar A, Nimesh S. Antibacterial and photocatalytic degradation efficacy of silver nanoparticles biosynthesized using Cordia dichotoma leaf extract. Adv Nat Sci Nanosci Nanotechnol 2016;7:045009.

20. Mei ML, Chu CH, Lo EC, Samaranayake LP. Fluoride and silver concentrations of silver diammine fluoride solutions for dental use. Int J Paediatr Dent 2013;23:279-85.

21. Reynolds EC, Cai F, Cochrane NJ, Shen P, Walker GD, Morgan MV, et al. Fluoride and casein phosphopeptide-amorphous calcium phosphate. J Dent Res 2008;87:344-8.

22. Huang R, Li M, Gregory RL. Bacterial interactions in dental biofilm. Virulence 2011;2:435-44.

23. Rosenblatt A, Stamford TC, Niederman R. Silver diamine fluoride: A caries "silver-fluoride bullet". J Dent Res 2009;88:116-25.

24. Takaisi-Kikuni NB, Schilcher H. Electron microscopic and microcalorimetric investigations of the possible mechanism of the antibacterial action of a defined propolis provenance. Planta Med 1994;60:222-7.

25. Targino AG, Flores MA, Dos Santos VE, de Godoy Bene Bezerra F, de Luna Freire H, Galembeck A, et al. An innovative approach to treating dental decay in children. A new anti-caries agent. J Mater Sci Mater Med 2014;25:2041-7. 
26. Fung M, Wong M, Lo E, Chu CH. Arresting early childhood caries with silver diamine fluoride-a literature review. J Oral Hyg Health 2013;1:1-5.

27. Ten Cate JM. Contemporary perspective on the use of fluoride products in caries prevention. Br Dent J 2013;214:161-7.

28. Lou YL, Botelho MG, Darvell BW. Reaction of silver diamine [corrected] fluoride with hydroxyapatite and protein. J Dent
2011;39:612-8.

29. Huang S, Zhang CP, Wang K, Li GQ, Hu FL. Recent advances in the chemical composition of propolis. Molecules 2014;19:19610-32.

30. Menon S, Agarwal H, Kumar SR, Kumar SV. Green synthesis of silver nanoparticles using medicinal plant Acalypha indica leaf extracts and its application as an antioxidant and antimicrobial agent against food borne pathogens. Int J Appl Pharm 2017;9:42-50. 